\title{
Corrigendum to "The UBO-TSUFD tsunami inundation model: validation and application to a tsunami case study focused on the city of Catania, Italy" published in Nat. Hazards Earth Syst. Sci., 13, 1795-1816, 2013
}

\author{
S. Tinti ${ }^{1}$ and R. Tonini ${ }^{2}$ \\ ${ }^{1}$ Dipartimento di Fisica e Astronomia (DIFA), Settore di Geofisica, Università di Bologna, viale Berti Pichat 8, 40127, \\ Bologna, Italy \\ ${ }^{2}$ Istituto Nazionale di Geofisica e Vulcanologia, Sezione di Bologna, via Donato Creti 12, 40128, Bologna, Italy \\ Correspondence to: R. Tonini (roberto.tonini@bo.ingv.it)
}

In the recently published paper "The UBO-TSUFD tsunami inundation model: validation and application to a tsunami case study focused on the city of Catania, Italy" by S. Tinti and R. Tonini, an incorrect caption of Table 2 appears.

The correct caption of Table 2 should read as follows:

"Seismic parameters of the two fault segments used for the simulation of the 1693 tsunami. The seismic moment $\left(M_{0}\right)$ is $6.41 \times 10^{21} \mathrm{Nm}$, and the corresponding moment magnitude $\left(M_{\mathrm{w}}\right)$ results to be 7.17 , assuming the rigidity parameter $\mu$ equal to $30 \mathrm{GPa}$. They are almost vertical normal faults, causing sea floor upheaval shoreward and subsidence seaward in the sea stretch off eastern Sicily from Catania (in the north) to Siracusa (in the south).” 